\title{
Mindfulness-Based Smoking Cessation Enhanced With Mobile Technology (iQuit Mindfully): Pilot Randomized Controlled Trial
}

Claire Adams Spears ${ }^{1}$, PhD; Lorien C Abroms ${ }^{2}, \mathrm{ScD}$; Carol R Glass ${ }^{3}, \mathrm{PhD}$; Donald Hedeker ${ }^{4}$, PhD; Michael P Eriksen ${ }^{1}$, ScD; Cherell Cottrell-Daniels ${ }^{1}, \mathrm{MPH}$; Binh Q Tran ${ }^{5}, \mathrm{PhD}$; David W Wetter ${ }^{6}, \mathrm{PhD}$

\footnotetext{
${ }^{1}$ Department of Health Policy and Behavioral Sciences, Georgia State University School of Public Health, Atlanta, GA, United States

${ }^{2}$ Prevention and Community Health, Milken Institute School of Public Health, George Washington University, Washington, DC, United States

${ }^{3}$ Department of Psychology, The Catholic University of America, Washington, DC, United States

${ }^{4}$ Department of Public Health Sciences, The University of Chicago, Chicago, IL, United States

${ }^{5}$ Department of Biomedical Engineering, The Catholic University of America, Washington, DC, United States

${ }^{6}$ Center for Health Outcomes and Population Equity, University of Utah and Huntsman Cancer Institute, Salt Lake City, UT, United States
}

\section{Corresponding Author:}

Claire Adams Spears, PhD

Department of Health Policy and Behavioral Sciences

Georgia State University School of Public Health

140 Decatur St SE

Atlanta, GA, 30303

United States

Phone: 14044139335

Email: cspears@gsu.edu

\section{Abstract}

Background: Mindfulness training shows promise for improving smoking cessation and lapse recovery, and between-session mobile health messages could enhance treatment engagement and effectiveness. Personalized, in-the-moment text messaging support could be particularly useful for low-income smokers with fewer smoking cessation resources.

Objective: This pilot study examined the feasibility of a text messaging program (iQuit Mindfully) as an adjunct to in-person Mindfulness-Based Addiction Treatment (MBAT) for smoking cessation.

Methods: A total of 71 participants were randomly assigned to MBAT ( $n=33)$ or iQuit Mindfully ( $n=38$; MBAT + between-session text messages); of these, 70\% (50/71) were African American, and 61\% (43/71) had an annual household income of US \$30,000 or less. All participants received 8 weekly therapist-led group counseling sessions, nicotine patches, and self-help materials. Outcomes were feasibility (attrition, engagement, and participants' ratings), participants' feedback regarding the text messaging intervention, and smoking cessation (assessed in person).

Results: Strong retention was achieved (76\% [54/71] at the end of treatment, and 89\% [63/71] at 1-month follow-up). In the iQuit Mindfully group, engagement was high (88\% [29/33] indicated reading all or most texts, and 89\% [34/38] engaged in interactive texting), and participants provided positive ratings (on a 1-10 scale, average rating for recommending the program to others was 8.4 [SD 2.5]). Participants indicated benefiting from the texts (eg, appreciating encouraging reminders, coping strategies, and social support) and suggested improvements (eg, more personalization). Overall, biochemically confirmed smoking cessation rates were $22 \%(12 / 55)$ at the end of treatment and 19\% (12/62) at 1-month follow-up, with no differences between conditions. Living below the poverty level predicted worse cessation outcomes at 1-month follow-up among participants receiving in-person only treatment $(P=.03)$ but not among those receiving iQuit Mindfully.

Conclusions: Text messaging appears to be a feasible and acceptable modality for supporting mindfulness-based smoking cessation treatment. The availability of $24 / 7$ text messaging might be particularly helpful for low-income smokers who have access to fewer cessation resources and experience significant day-to-day barriers to quitting.

Trial Registration: ClinicalTrials.gov NCT03029819; https://clinicaltrials.gov/ct2/show/NCT03029819

(JMIR Mhealth Uhealth 2019;7(6):e13059) doi: $\underline{10.2196 / 13059}$ 


\section{KEYWORDS}

text messaging; smoking cessation; low-income populations

\section{Introduction}

\section{Background}

Smoking is the leading cause of premature death in the United States [1]. Only $7 \%$ of smokers quit each year despite most indicating an interest in quitting [2], and profound tobacco-related health disparities exist [3]. Smoking prevalence remains disproportionately high among adults with low socioeconomic status (SES) despite substantial decline in the smoking rate in the general US population [3-5]. One-fourth $(25.3 \%)$ of adults living below the federal poverty line smoke, compared with only $14.3 \%$ of those at or above the poverty level [5]. Low-SES smokers and members of certain racial and ethnic minority groups, including African Americans, often have greater difficulty quitting and have higher incidence and mortality rates for tobacco-related cancers [2,3,6,7]. Smokers with poorer financial, structural, and social resources face formidable day-to-day barriers, including societal (eg, low health care access), community (eg, tobacco advertising and neighborhood stress), interpersonal (eg, social norms for smoking and low social support), and intrapersonal factors (eg, high stress and low self-efficacy) [3,6,8], which promote addiction and impede efforts to quit. Improving on evidence-based smoking cessation interventions for low-SES and racial and ethnic minority populations will be critical for targeting tobacco-related health disparities.

\section{Mindfulness-Based Programs for Smoking Cessation}

Training in mindfulness (ie, purposeful, nonjudgmental, present-focused attention $[9,10]$ ) shows promise for increasing rates of smoking cessation and lapse recovery [11,12]. Mindfulness refers to one's relationship with his or her thoughts and emotions (ie, observing these experiences nonjudgmentally, without reacting or trying to change them) rather than to their content. A meta-analysis of randomized controlled trials (RCTs) found that participants receiving mindfulness interventions were almost twice as likely to achieve smoking abstinence for more than 4 months compared with those receiving usual care $(25.2 \%$ vs $13.6 \%$ ) [13]. There is a dearth of research on mindfulness in low-SES and racial and ethnic minority groups, but mindfulness does show promise for smoking cessation in these populations $[14,15]$. Programs that teach nonjudgmental, self-compassionate awareness could be particularly useful for racial and ethnic minority populations [16] and have been perceived as empowering among low-SES and racial minority adults [17]. However, additional between-session support may be needed for low-SES and racial and ethnic minority smokers, who experience significant day-to-day barriers to quitting and have lower access to smoking cessation resources.

\section{Mobile Health and Smoking Cessation}

Mobile health (mHealth) interventions have promise for encouraging skills on a real-time, real-life basis, thus increasing skill level, self-efficacy, and the likelihood that the skill will become a part of daily routines [18]. mHealth messages could encourage participants to use mindfulness and other smoking cessation strategies in moments of high stress or craving. This type of in-the-moment support could be especially beneficial for populations (eg, low-SES smokers) with fewer cessation resources. Recent research supports the promise of technology (eg, Web-based training and mobile apps) for teaching mindfulness [19,20], including for smoking cessation [21-23]. Although mindfulness apps have been proliferating, most mHealth mindfulness programs have not been rigorously tested [24].

There is strong empirical support for text messaging programs for smoking cessation [25-30], although none to our knowledge has focused on mindfulness. In a systematic review, mobile phone interventions (most using text messaging) increased smoking abstinence at 6 months (risk ratio $[R R]=1.67$ ), with even more positive findings for biochemically verified abstinence $(\mathrm{RR}=1.83$ ) [26]. Text messaging does not require a smartphone, internet access, or high technical literacy, thus meeting the needs of many adults with lower SES. For example, the vast majority $(91 \%)$ of college graduates own a smartphone compared with only $57 \%$ of adults with less than high school education [31]. However, $90 \%$ of Americans with less than high school education own a mobile phone [31]. Furthermore, low-SES and certain racial and ethnic minority adults use text messaging particularly often. In a Pew Research Center study, mean number of texts sent/received per day for Caucasians, African Americans, and Latinos were 31.2 (median 10), 70.1 (median 20), and 48.9 (median 20), respectively. Whereas mean texts per day among adults with college education or greater was 23.8 (median 10), those with less than high school education sent/received 69.4 texts per day (median 20) [32]. Text messaging can provide strategies and encouragement in the context of everyday life and in real time (eg, in moments of high stress or craving), and the content of messages can be personalized. As an adjunct to in-person mindfulness treatment, between-session text messaging could increase treatment engagement and provide vital 24/7 support for smokers from disadvantaged backgrounds.

\section{iQuit Mindfully}

Recognizing that most mHealth programs have been developed without adequate feedback from the target population [33], we took a user-centered design approach [34,35] to develop a text messaging smoking cessation program for predominantly low-SES, racially/ethnically diverse smokers. As described in detail elsewhere [36], we conducted 2 phases of formative research (initial focus groups before developing text message content, and then an abbreviated 1-week trial of text messages) to gather qualitative data to inform and improve the text messaging program. User feedback was elicited throughout the process of developing and refining the messages. The text messages were designed to be sent between weekly in-person mindfulness treatment sessions for smoking cessation.

This study is a pilot investigation of mindfulness-based smoking cessation that incorporates this between-session text messaging (iQuit Mindfully). To our knowledge, this is the first study to 
use text messaging to enhance mindfulness-based smoking cessation treatment. Participants were randomly assigned to 1 of 2 groups: Mindfulness-Based Addiction Treatment (MBAT) or iQuit Mindfully (MBAT with the addition of between-session text messages). Feasibility and acceptability outcomes critical to this pilot study were attrition, participant engagement with text messages, and participant ratings and feedback regarding the text messaging program. The primary smoking cessation outcome was 7 consecutive days of abstinence from smoking at the end of treatment. In addition, secondary analyses examined associations among engagement with text messaging, mindfulness practice, and smoking cessation, as well as cessation outcomes by poverty status.

\section{Methods}

\section{Participants}

Recruitment targeted a racially/ethnically diverse sample of smokers with relatively low income levels in the Atlanta, GA, area. Inclusion criteria were age 18 to 65 years; current smoker with history of $\geq 5$ cigarettes per day for the past year (and expired carbon monoxide $[\mathrm{CO}] \geq 6 \mathrm{ppm}$ ); motivated to quit within the next 30 days; valid home address in the greater Atlanta area; functioning telephone number; owning a mobile phone with text messaging capacity; ability to speak, read, and write in English; and marginal/adequate health literacy (at least a sixth grade level) as determined by the Rapid Estimate of Adult Literacy in Medicine [37]. Exclusion criteria were contraindication for the nicotine patch; past 30-day use of recreational drugs, alcohol-related problems (positive response on 2 or more of the 5 Patient Health Questionnaire [PHQ] Alcohol Abuse/Dependence Scale items [38]), self-reported current diagnosis of schizophrenia or bipolar disorder or use of antipsychotic medications, score of $\geq 3$ on the PHQ-2 [39] depression screening instrument, regular use of tobacco products other than cigarettes (electronic cigarette users were not excluded), current use of tobacco cessation medications, pregnancy or lactation, or another household member enrolled in the study. The study was approved by the university's institutional review board, and written informed consent was obtained from all participants.

\section{Procedures}

Participants were recruited through flyers (posted at venues including the university's downtown campus, local hospitals/community health centers, and near bus and train stops), Web-based sources (eg, Craigslist, listservs), and word of mouth. After screening and informed consent procedures, participants were randomly assigned to iQuit Mindfully (MBAT with text messaging) or MBAT (without text messaging). Randomization took place at the end of the baseline session, after baseline assessments had been administered. Permuted block randomization, with stratification based on age (ages 18-49 vs 50-65 years), was used to allocate participants to treatment condition. Co-author DH used SAS software (SAS Institute Inc) to generate the random number sequence. A graduate research assistant (unaware of the size of the blocks) allocated interventions through opaque sealed envelopes marked according to the allocation schedule. The majority of study personnel were masked to treatment condition. Limited staff were unmasked to handle randomization codes (ie, the graduate research assistant) and delivery of interventions (ie, the study therapist). Participants were recruited between January and June 2017; interventions were delivered between February and September 2017; and follow-up assessments were conducted between May and October 2017.

\section{Study Interventions}

All participants received in-person group treatment based on the 8-week MBAT protocol [12], in addition to the 6 weeks of nicotine patch therapy and self-help materials based on the Treating Tobacco Use and Dependence Clinical Practice Guideline [40]. Patch therapy (beginning on the quit day) for participants who smoked more than 10 cigarettes per day consisted of 4 weeks of $21 \mathrm{mg}$ patches, 1 week of $14 \mathrm{mg}$ patches, and 1 week of $7 \mathrm{mg}$ patches. Patch therapy for those who smoked 5 to 10 cigarettes per day consisted of 4 weeks of 14 $\mathrm{mg}$ patches and 2 weeks of $7 \mathrm{mg}$ patches.

MBAT was provided by a master's level licensed professional counselor with formal training in mindfulness and addictions. MBAT closely follows Mindfulness-Based Cognitive Therapy [41] procedures but replaces the depression-related material with nicotine dependence-related material. The program consists of 8 weekly 2-hour sessions. Aims are to help participants increase moment-to-moment awareness of thoughts, feelings, and sensations; observe these sensations nonjudgmentally; and learn to disengage their attention and choose more skillful responses (rather than automatic reactions) to uncomfortable sensations (including cravings) and high-risk situations. To provide additional support on the quit date and encourage further mindfulness practice, session 5 (quit date) was an extended 4-hour session. MBAT emphasizes daily practice in several forms: formal sitting meditation, body scan meditation, walking meditation, eating meditation, and gentle yoga. There were between 8 and 15 participants in the MBAT group sessions.

Participants in the iQuit Mindfully condition also received approximately 2 to 6 text messages per day on each day between treatment sessions. Texts were sent using the Mobile Commons/Upland Mobile Messaging platform. The content and frequency of messages were revised based on focus groups and pilot testing with low-income, racially/ethnically diverse smokers [36]. Text messages reminded participants to practice mindfulness (eg, reminders for informal practice, such as awareness of the breath throughout the day, and reminders for formal practice, such as the body scan and sitting meditation). Text messages were personalized (eg, reminding participants of their personal reasons to quit and amount of money to be saved as a result of quitting; incorporating first names) and interactive (eg, participants were asked questions such as "Good morning, John! Would you like to try a mindfulness exercise?" and "There are people, places, and things that make you want to smoke. What are your top 3 triggers to smoke?"), and automated text responses were sent based on their replies. Texts also provided specific strategies to aid in cessation (eg, reminders to get rid of cues to smoke, reach out for social support, and coping strategies taught in MBAT). 
Participants received approximately 2 messages per day during week 1, 3 per day during week 2, 4 per day during week 3,5 per day during week 4,6 per day during week 5,4 per day during week 6 , and 3 per day during week 7 . This message schedule was based on our earlier qualitative work [36]. Participants could also text specified words (CRAVE, STRESS, or SLIP) at any point to receive additional text message support for coping with cravings, stress, or smoking lapses, respectively. Participants received a relatively small number of texts (1-3 per week) during the 1-month follow-up period and had the opportunity to text the CRAVE/STRESS/SLIP keywords during this time.

\section{Measures}

\section{Demographics and Baseline Smoking Behavior}

At baseline, participants indicated their gender, age, education, income, and employment status. Poverty status (below vs at or above the federal poverty line) was calculated according to US Census Bureau Guidelines based on family size and number of children [42]. The Heaviness of Smoking Index, a strong indicator of nicotine dependence [43], assessed self-reported average number of cigarettes smoked per day and the time to first cigarette on waking.

\section{Participants' Ratings and Feedback Regarding iQuit Mindfully}

Participants in the iQuit Mindfully condition completed program evaluation forms in person at the end of treatment. Participants were asked, "Of all of the text messages that you received as part of this program, how many did you read?" (response options: none, some, most, or all). They were also asked, "Overall, how helpful were the text messages in getting you to try to quit smoking?" (rated from $1=$ not at all helpful to $10=$ extremely helpful), and then specifically asked about the helpfulness of the CRAVE, STRESS, and SLIP keywords using the same 10-point scales. They were prompted to "Please circle the number that best represents whether you would recommend that other people receive the text messages that you received in this program (or similar texts) as a way to help them quit smoking" (rated from 1=would not recommend to $10=$ would definitely recommend). It was determined a priori that scores of 6 or more on these 10-point scales would indicate that the texts were acceptable. Participants were also asked, "Please rate the overall number of text messages that you received as part of this program": (response options: "not enough texts," "prefer more texts," "about the right number of texts," "prefer fewer texts," and "way too many texts").

Finally, participants were asked the following open-ended questions:

- What did you like the most about the text messages?

- How, if at all, did you find the text messages to be helpful? (these 2 items were combined for analysis given considerable overlap)

- What, if anything, did you dislike about the text messages?

- What recommendations do you have to improve the text messages?

\section{Smoking Abstinence}

Smoking abstinence at the end of treatment (3 weeks after quit date) and 1-month follow-up (7 weeks after quit date) was defined as self-reported complete abstinence for 7 days that was biochemically confirmed in person with $\mathrm{CO}<6 \mathrm{ppm}$. Participants who denied smoking for the past 7 days but had CO levels $\geq 6$ ppm were coded as not abstinent ( $n=4$ at the end of treatment and $n=2$ at follow-up). Missing data were not coded as smoking because of the potential for severe bias that has been demonstrated in prior studies $[44,45]$.

\section{Weekly Mindfulness Practice}

Each week from treatment session 2 to session 8, participants completed a weekly mindfulness practice $\log$ [12] to indicate the number of days that they practiced each of 5 core mindfulness techniques taught in treatment (sitting meditation, body scan, walking meditation, yoga/mindful stretching, and mindful awareness of breath during the day) during the past week. Responses were averaged for each mindfulness practice over the course of treatment.

\section{Data Analysis}

Descriptive statistics provided information on feasibility and acceptability (ie, attrition, engagement, and participants' ratings). Open-ended responses to program evaluations were coded using QSR International's NVivo 11 software. The first author (CAS) and coauthor CCD each reviewed the responses to develop an initial set of themes and then collaborated to define specific codes and refine the coding manual. CAS and CCD then each separately coded all the responses, with an overall kappa of .95, indicating high interrater reliability. Discrepancies were resolved through discussion, with final decisions made by the first author. Chi-square tests examined group differences in smoking cessation outcomes at the end of treatment and 1-month follow-up. Independent samples $t$ tests examined group differences in mindfulness practice over the course of treatment.

In addition, 2 ancillary analyses were conducted. First, to examine whether participants who were more engaged with the text messages and/or practiced mindfulness more frequently between sessions had better outcomes, associations among text message engagement (based on the number of times participants texted the system), weekly mindfulness practice variables, and abstinence were examined using chi-square, $t$ tests, and logistic regression. Second, because the text messages were specifically designed to target low-SES smokers, analyses examined results separately by poverty status (below vs at or above the federal poverty line).

\section{Results}

\section{Screening and Enrollment}

A total of 266 individuals completed telephone screening, 100 completed in-person screening, and 72 participants were enrolled in the study (Figure 1). Overall, 1 participant in the iQuit Mindfully condition was removed because of disruptive behavior in the in-person group treatment for a final analytic sample of 71. 
Figure 1. Consolidated Standards of Reporting Trials flow diagram. CPD: cigarettes per day; MBAT: Mindfulness-Based Addiction Treatment; NRT: nicotine replacement therapy; REALM: Rapid Estimate of Adult Literacy in Medicine.

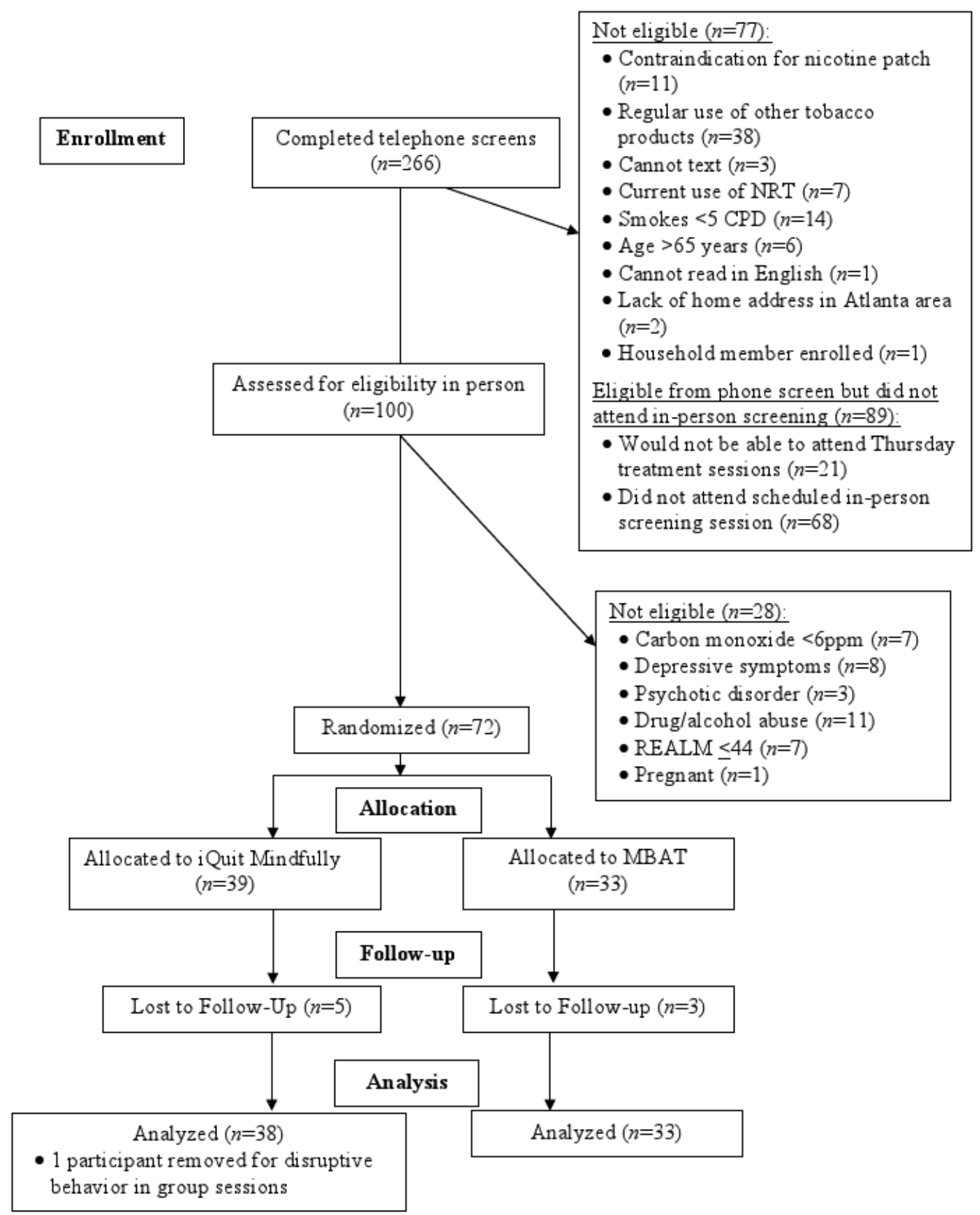

\section{Participants' Characteristics}

Demographic and smoking-related characteristics at baseline are shown in Table 1. Mean age of the participants was 45.6 years (SD 12.1), and about half $(37 / 71,52 \%)$ were female. Most participants were African American (50/71, 70\%), 15 (21\%) were Caucasian, and $4(6 \%)$ reported more than 1 race. Most $(43 / 71,61 \%)$ indicated having an annual household income of US $\$ 30,000$ or less, and $41 \%(27 / 66)$ were living below the federal poverty line. On average, participants smoked 16.5 (SD
9.6) cigarettes per day at baseline and had been smoking daily for 23.6 (SD 14.1) years. The majority $(57 / 71,80 \%)$ reported smoking their first cigarette within 30 min of waking, and most $(57 / 71,80 \%)$ smoked primarily menthol cigarettes. Although statistical tests were not conducted to examine baseline differences between treatment groups [46,47], examination of the descriptive statistics suggests that participants in the iQuit Mindfully condition were more likely to be African American and have lower SES than those in MBAT. 
Table 1. Participants' characteristics.

\begin{tabular}{|c|c|c|c|}
\hline Demographic characteristics & Full sample $(\mathrm{N}=71)$ & iQuit Mindfully $(\mathrm{n}=38)$ & $\begin{array}{l}\text { Mindfulness-Based Addiction } \\
\text { Treatment }(\mathrm{n}=33)\end{array}$ \\
\hline Age (years), mean (SD) & $45.6(12.1)$ & $45.6(12.4)$ & $45.6(12.0)$ \\
\hline Gender, female, n (\%) & $37(52)$ & $17(45)$ & $20(61)$ \\
\hline \multicolumn{4}{|l|}{ Race/ethnicity, n (\%) } \\
\hline Black/African American & $50(70)$ & $34(89)$ & $16(49)$ \\
\hline Caucasian & $15(21)$ & $4(11)$ & $11(33)$ \\
\hline Asian & $1(1)$ & $0(0)$ & $1(3)$ \\
\hline More than 1 race & $4(6)$ & $0(0)$ & $4(12)$ \\
\hline Other & $1(1)$ & $0(0)$ & $1(3)$ \\
\hline Hispanic/Latino & $3(4)$ & $1(3)$ & $2(6)$ \\
\hline \multicolumn{4}{|l|}{ Employment, n (\%) } \\
\hline Regular full-time work (40+ hours/week) & $17(24)$ & $6(16)$ & $11(33)$ \\
\hline Regular part-time work & $13(18)$ & $3(8)$ & $10(30)$ \\
\hline Temporary part-time work & $1(1)$ & $1(3)$ & $0(0)$ \\
\hline Self-employed & $1(1)$ & $1(3)$ & $0(0)$ \\
\hline Student & $4(6)$ & $2(5)$ & $2(6)$ \\
\hline Unemployed & $19(27)$ & $15(39)$ & $4(12)$ \\
\hline Retired & $10(14)$ & $5(13)$ & $5(15)$ \\
\hline Unable to work or disabled & $6(9)$ & $5(13)$ & $1(3)$ \\
\hline \multicolumn{4}{|l|}{ Education, $n(\%)$} \\
\hline Less than high school degree & $12(17)$ & $7(18)$ & $5(15)$ \\
\hline High school degree or General Education Development & $14(20)$ & $7(18)$ & $7(21)$ \\
\hline Some college/technical school & $19(27)$ & $12(32)$ & $7(21)$ \\
\hline Associates degree & $10(14)$ & $4(11)$ & $6(18)$ \\
\hline Bachelor's degree & $10(14)$ & $5(13)$ & $5(15)$ \\
\hline Some postbac school & $3(4)$ & $3(8)$ & $0(0)$ \\
\hline Graduate degree & $3(4)$ & $0(0)$ & $3(9)$ \\
\hline \multicolumn{4}{|l|}{ Annual household income in US dollars $(n=66), n(\%)$} \\
\hline$\leq \$ 12,000$ & $20(30)$ & $12(36)$ & $8(24)$ \\
\hline$\$ 12,001-\$ 18,000$ & $10(15)$ & $7(21)$ & $3(9)$ \\
\hline$\$ 18,001-\$ 30,000$ & $13(20)$ & $5(15)$ & $8(24)$ \\
\hline$\$ 30,001-\$ 42,000$ & $7(11)$ & $2(6)$ & $5(15)$ \\
\hline$\$ 42,001-\$ 54,000$ & $2(3)$ & $0(0)$ & $2(6)$ \\
\hline$\$ 60,001-\$ 84,000$ & $4(6)$ & $0(0)$ & $4(12)$ \\
\hline$>\$ 84,000$ & $10(15)$ & $7(21)$ & $3(9)$ \\
\hline \multicolumn{4}{|l|}{ Poverty status (n=66), n (\%) } \\
\hline Below poverty threshold & $27(41)$ & $16(48)$ & $11(33)$ \\
\hline At or above poverty threshold & $39(59)$ & $17(52)$ & $22(67)$ \\
\hline Cigarettes per day, mean (SD) & $16.5(9.6)$ & $14.4(9.4)$ & $18.8(9.3)$ \\
\hline Years smoking daily, mean (SD) & $23.6(14.1)$ & $20.7(13.1)$ & $27.0(14.6)$ \\
\hline \multicolumn{4}{|l|}{ Time to first cigarette, n (\%) } \\
\hline Within $5 \mathrm{~min}$ & $27(38)$ & $17(45)$ & $10(30)$ \\
\hline
\end{tabular}




\begin{tabular}{clll}
\hline Demographic characteristics & Full sample (N=71) & iQuit Mindfully (n=38) & $\begin{array}{l}\text { Mindfulness-Based Addiction } \\
\text { Treatment }(\mathrm{n}=33)\end{array}$ \\
\hline $6-30$ min & $30(42)$ & $15(39)$ & $15(45)$ \\
$31-60$ min & $7(10)$ & $3(8)$ & $4(12)$ \\
After 60 min & $7(10)$ & $3(8)$ & $4(12)$ \\
Menthol cigarettes as regular brand, $\mathrm{n}(\%)$ & $57(80)$ & $33(87)$ & $24(73)$ \\
\hline
\end{tabular}

\section{Treatment Attendance}

Participants attended an average of 5.7 of 8 treatment sessions (SD 2.7), with no difference between conditions (iQuit Mindfully: 5.9 sessions, SD 2.7; MBAT: 5.4 sessions, SD 2.8), $P=.50$. Greater treatment attendance predicted higher likelihood of smoking cessation at the end of treatment $(\beta=4.05, P=.049)$ and approached significance in predicting cessation at 1-month follow-up $(\beta=1.76, P=.058)$.

\section{Feasibility and Acceptability}

\section{Attrition}

A priori, it was deemed that $35 \%$ attrition would be acceptable (based on 34\% attrition in trial of MBAT by Vidrine et al [12]). Overall attrition rates were $24 \%$ (17/71) at the end-of-treatment assessment and $11 \%(8 / 71)$ at 1-month follow-up, with no differences between groups (attrition at the end of treatment: iQuit Mindfully 21\% [8/38], MBAT 27\% [9/33], $P=.38$; attrition at 1-month follow-up: iQuit Mindfully $11 \%$ [4/38], MBAT $12 \%$ [4/33], $P=.83)$.

\section{iQuit Mindfully Engagement}

Level of engagement was determined based on (1) the proportion of texts that participants indicated reading (we expected that at least $75 \%$ would read most or all texts, based on the study by Abroms et al [48]) and (2) responses to interactive text messages (we expected that at least $85 \%$ of participants would respond to at least one of the interactive text messages or use the CRAVE, STRESS, or SLIP keywords at least once, based on the study by Heminger et al [49]). These benchmarks were achieved. The majority $(88 \%, 29 / 33)$ indicated reading all or most text messages, and $89 \%$ (34/38) responded to at least one of the interactive text messages or used the CRAVE, STRESS, or SLIP keywords.

\section{Participants' Ratings and Feedback}

On a scale of 1 to 10 , participants' average rating of text helpfulness was 8.0 (SD 2.4). Ratings regarding the helpfulness of the keywords CRAVE, STRESS, and SLIP were 7.8 (SD 0.29), 7.9 (SD 2.7), and 7.8 (SD 2.8), respectively. On a scale of 1 to 10 , participants' average rating of the extent to which they would recommend the text messaging program to others was 8.4 (SD 2.5). Most $(58 \%, 19 / 33)$ indicated receiving about the right number of texts, $30 \%(10 / 33)$ preferred fewer, and $12 \%$ (4/33) preferred more.

Table 2 shows themes and illustrative quotations from participants' open-ended responses on iQuit Mindfully program evaluations. Overall, participants reported positive experiences with the text messages (eg, "I loved them; sometimes I read them going to bed instead of smoking"). Almost all (97\%, 32/33) provided positive responses when asked what they liked and what was most helpful about the texts. Themes were appreciating the positive tone $(n=13)$, receiving reminders $(n=11)$, benefiting from mindfulness $(n=9)$, perceiving a sense of social support $(n=9)$, perceiving that the messages had good timing $(n=6)$, noting that the messages encouraged self-compassion in the face of smoking lapses $(n=6)$, and receiving specific strategies to cope with cravings and stress $(\mathrm{n}=5)$. When asked what they disliked, 61\% (20/33) responded nothing, N/A, or left the question blank. Whereas 9 participants indicated that there were too many text messages or that they were repetitive, 7 indicated wanting more text messages. When asked their suggestions for improvements, 67\% (22/33) responded none, N/A, or left the question blank. Of those who provided feedback, suggestions included connecting participants to additional outside resources $(\mathrm{n}=5$; eg, connect to phone call, emergency resources, one-on-one support), incorporating more personalization $(n=3)$, and including more religion/spirituality in the messages $(n=3)$.

\section{Smoking Abstinence}

There were no significant differences between groups either at the end of treatment (iQuit Mindfully: 26\% [8/31]; MBAT: 17\% [4/24], $P=.42$ ) or follow-up (iQuit Mindfully: 16\% [5/32]; MBAT: $23 \%$ [7/30], $P=.44)$.

\section{Weekly Mindfulness Practice}

Mean number of days engaging in each type of mindfulness practice per week ranged from 2.02 (SD 1.72) for yoga to 3.25 (SD 2.11) for mindful awareness of breathing. There were no significant between-group differences, $P>.59$.

\section{Associations Among Text Engagement, Weekly Mindfulness Practice, and Abstinence}

Among iQuit Mindfully participants, the mean number of times participants texted the system was 55.2 (SD 63.1; median 37) and was highly skewed (7 participants texted over 100 times, with 2 of these texting over 200 times). Thus, a dichotomized text engagement variable was created based on the median. Participants categorized as having high engagement had significantly higher abstinence rates at the end of treatment than those with low engagement, $\chi_{1}^{2}=7.8, P=.005$. Whereas $44 \%$ (8/18) of participants with high engagement were abstinent at the end of treatment, none of those with low engagement was abstinent. Engagement was not significantly associated with abstinence at 1-month follow-up (7\% [1/14] of those with low engagement vs $22 \%$ [4/18] of those with high engagement were abstinent, $P=.24)$. 
Table 2. Example quotations from open-ended iQuit Mindfully program evaluation responses.

\begin{tabular}{|c|c|}
\hline Themes & Example quotations \\
\hline \multicolumn{2}{|l|}{ Most helpful aspects } \\
\hline Positive tone & $\begin{array}{l}\text { - "Positive response was really cool for my confidence" } \\
\text { - "Positive and uplifting" }\end{array}$ \\
\hline Reminders & $\begin{array}{l}\text { - "They became an integral part of your day and served as gentle reminders and encourage- } \\
\text { ment" } \\
\text { - "They reminded me of my goals and told me why I was choosing to quit smoking" }\end{array}$ \\
\hline Mindfulness & $\begin{array}{l}\text { - } \quad \text { "Helped me to stay mindful" } \\
\text { - "Kept me aware" } \\
\text {-Stop breathe think" }\end{array}$ \\
\hline Social support & $\begin{array}{l}\text { - "I felt that someone cared how I was feeling" } \\
\text { - "I was able to reach out for support and it was very helpful" } \\
\text { - "It let me know somebody out there to help me" }\end{array}$ \\
\hline Good timing & $\begin{array}{l}\text { - "Sometimes they came right on time. I would start thinking about smoking and here comes } \\
\text { that text." } \\
\text { - "Every time I thought about smoking I get that text of encouragement to not smoke." }\end{array}$ \\
\hline $\begin{array}{l}\text { Self-compassion in the context of smoking } \\
\text { lapses }\end{array}$ & $\begin{array}{l}\text { - "They encouraged me to continue with my journey and don't worry about the slip up and } \\
\text { - "Must start over." }\end{array}$ \\
\hline Strategies for coping with cravings and stress & $\begin{array}{l}\text { - "If you text CRAVE and actually do what the text message says you will successfully } \\
\text { overcome that current craving" } \\
\text { - "You were given techniques to help overcome the stress" }\end{array}$ \\
\hline
\end{tabular}

\section{Dislikes}

Too many text messages/repetitive

- "Came a little too quick sometimes"

- "Repetitive"

- "Less texts would be better"

Not enough text messages

- " "I disliked] when they became less frequent"

- "Even more would be helpful"

\section{Suggestions}

Connect to outside resources

- "One on one support. Additional resources"

- "Maybe a call"

More personalization

- "Really try to find out what best suits each individual"

- "More intuitive and spontaneous and less generically programmed"

Religion/spirituality

- "Send Bible verses/scriptures"

- "More spiritual texts"

Associations between engagement with text messages and mindfulness practice were also examined. Participants who showed high text engagement reported practicing informal mindfulness more frequently than those with low engagement (high engagement: mean 3.9 [SD 2.0] days vs low engagement: mean 2.0 [SD 1.6] days), $t_{32}=2.91, P=.006$. The association between text engagement and frequency of sitting meditation practice approached significance (high engagement: mean 3.2 [SD 1.7] days vs low engagement: mean 2.2 [SD 1.5] days), $t_{32}=1.85, P=.07$. There were no differences in frequency of other mindfulness practices by the level of text engagement. When mindfulness practice variables were entered simultaneously into a logistic regression analysis predicting abstinence outcomes, mindful awareness of the breath uniquely predicted greater likelihood of abstinence at the end of treatment $(\beta=1.60, P=.04)$ and 1-month follow-up $(\beta=1.99, P=.008)$.

\section{Associations Between Poverty Status and Abstinence Outcomes by Condition}

Among participants living in poverty, 23\% (3/13) of those in iQuit Mindfully were abstinent at the end of treatment and 1-month follow-up, whereas none of the participants in the control group receiving MBAT quit smoking at either time point. Fisher's exact tests examined associations between poverty status and abstinence separately by condition. Poverty status was not significantly associated with abstinence at the end of treatment (MBAT: $P=.26$; iQuit Mindfully: $P=.67$ ). At 
1-month follow-up, living below the poverty level was associated with worse cessation outcomes among MBAT participants $(P=.03)$ but not among those receiving iQuit Mindfully $(P=.65)$.

\section{Discussion}

\section{Principal Findings}

This pilot study examined the feasibility of a mindfulness-based smoking cessation program incorporating between-session text messaging (iQuit Mindfully). To our knowledge, this is the first study to use text messaging to enhance mindfulness-based smoking cessation treatment, and preliminary results support the feasibility and acceptability of text messaging for providing day-to-day smoking cessation support to low-SES, racially/ethnically diverse adults. Strong retention was achieved (76\% [54/71] at the end of treatment, and 89\% [63/71] at 1-month follow-up); engagement in iQuit Mindfully was high (88\% [29/33] indicated reading all or most text messages, and $89 \%$ [34/38] texted the system); and participants provided positive ratings and feedback about the text messages. Between-session text messaging could be particularly beneficial for promoting smoking cessation among low-SES adults. Participants provided suggestions for further improving the text messaging program, and the results of this study warrant additional investigation in a larger RCT.

The overall biochemically confirmed smoking cessation rates were $22 \%(12 / 55)$ at the end of treatment and 19\% (12/62) at 1-month follow-up, with no differences between conditions. Living below the poverty level predicted worse cessation rates at 1-month follow-up in participants receiving in-person MBAT only, but not among those receiving iQuit Mindfully text messages. Smokers living in poverty not only have lower health care access but also are continually confronted with more tobacco advertising, higher social norms for smoking, and lower social support for quitting and experience higher stress and lower self-efficacy for quitting [3,6,8]. The availability of 24/7 text messaging support could be vital for helping low-SES smokers to overcome these chronic, day-to-day barriers. This study is limited by small sample size, and further investigation in a larger, appropriately powered trial is needed. Extant studies do support the use of mobile phone-delivered interventions for smoking cessation specifically among low-income smokers [50].

\section{Comparison With Prior Work}

Participants who were more engaged with the iQuit Mindfully text messaging program practiced informal mindfulness more frequently and were more likely to quit smoking at the end of treatment. This is consistent with past research, suggesting that higher engagement with mHealth programs predicts better smoking cessation outcomes [51-53]. However, low user engagement is a pervasive problem with mHealth programs $[24,54]$, and efforts are needed to increase engagement with the ultimate goal of improving outcomes. One strategy suggested by our participants is to further personalize text messages, and extant research suggests that tailoring interventions to users' needs and preferences can indeed increase engagement and efficacy [55-57]. We also examined associations between treatment condition and in-person session attendance. There were no differences in attendance between MBAT and iQuit Mindfully participants, but those who attended more sessions were more likely to quit smoking. Future research might consider how technology could increase in-person session attendance as well as engagement during these sessions.

Greater informal mindfulness practice (ie, mindful attention to breathing throughout the day) predicted higher likelihood of smoking abstinence at both end of treatment and 1-month follow-up. Although more frequent personal mindfulness practice is hypothesized to confer psychosocial benefits, the literature on associations between mindfulness practice and clinical outcomes has been somewhat mixed [58-60]. Past research has shown positive associations between mindfulness practice and better smoking cessation outcomes [11]. The findings of this study suggest that apart from formal meditation practice, mindful attention to breathing in the context of daily activities is uniquely associated with better smoking cessation outcomes. This informal practice (eg, taught through the STOP [Stop, Take a breath, Observe, Proceed] acronym in MBAT and other mindfulness programs) could be especially useful for coping with cravings and other stressors during the cessation process.

Overall, iQuit Mindfully participants noted positive experiences with the text messages. Themes included appreciating the positive tone, reminders, mindfulness techniques, social support, timing of the messages, self-compassion in the face of smoking lapses, and coping strategies. This is consistent with our past qualitative work developing iQuit Mindfully [36] as well as other qualitative studies of adults' experiences with text messaging for smoking cessation [61,62]. A common theme across studies is that although participants understand that the texts are automated, they often describe a sense of social support (eg, "It's like having a friend who texts you when you are feeling stressed or having a feeling like you want to smoke" [36]). Our participants suggested that the program be even more personalized, and future iterations of the program might provide more flexibility and personalization in terms of frequency, timing, and content of text messages (eg, varying the number and timing of texts based on individual preferences and triggers). As suggested by participants, text messages could also include more religious/spiritual content (this could also be personalized based on individual preferences) and connect them to outside resources (eg, direct connection to quitlines or other support as needed). In addition, the research team noted some logistical issues with participants using their own mobile phones during the study (eg, service interruptions and changing phone numbers), and future studies might offer participants mobile phones with wireless plans to use for the duration of the study. It is possible that these issues may become less common over time, as mobile phone access continues to increase in low-SES populations $[63,64]$.

\section{Limitations}

This pilot study is limited by a small sample size without statistical power to detect group differences in smoking cessation or other outcomes. Although modeling-based approaches can help to address pitfalls of as-treated analyses [65], our sample 
was too small to fit such models, and results should be viewed as preliminary evidence of feasibility that will need to be tested in larger trials. In addition, iQuit Mindfully text messages were designed to supplement (rather than replace) in-person MBAT sessions, and thus, this program also involves the substantial time and resources associated with in-person treatment. Our decision to include both in-person treatment and text messaging was based on our formative work with low-SES smokers, who noted that text messaging alone (in the absence of other resources such as in-person treatment) would not be sufficient [36]. However, future iterations might consider fully implementing the program through mHealth to increase scalability and reduce costs. In addition, results may or may not generalize to those not included based on the eligibility criteria (eg, people using multiple forms of tobacco, those with psychotic disorders or drug/alcohol abuse). Finally, frequency of between-session mindfulness practice was relatively low in both MBAT and iQuit Mindfully conditions. This is consistent with other research finding that participants often do not practice mindfulness as frequently as directed [12]. Research is needed to examine strategies to promote mindfulness practice among smokers, and as discussed above, more tailored messaging could be one such strategy. Despite limitations, this pilot study is strengthened by the use of biochemical confirmation of smoking behavior; recruitment of predominantly low-SES, racial minority adults; and RCT design, all of which support feasibility for conducting an efficacy RCT.

\section{Conclusions}

Overall, this proof-of-concept study provides strong evidence for feasibility and acceptability of iQuit Mindfully text messages to enhance MBAT by providing between-session support. Offering tailored 24/7 text messaging support could be helpful for low-SES smokers, who have lower access to cessation support and face formidable day-to-day barriers to quitting. Preliminary findings warrant further investigation in an appropriately powered RCT to determine efficacy.

\section{Acknowledgments}

This work was supported by the National Center for Complementary and Integrative Health (K23AT008442). DWW is supported by the Huntsman Cancer Foundation, the National Cancer Institute (P30CA042014), and the National Center for Advancing Translational Sciences (UL1TR001067). The content is solely the responsibility of the authors and does not necessarily represent the official views of the National Institutes of Health. The authors thank Mark Dannenfelser for leading MBAT groups and Brittani Carter, Sharrill Bell, Charlayne Scarlett, Maitreyi Bandlamudi, Amanda Grant, and Jasmine Guo for their help with data collection. They also thank Drs Sarah Bowen, Bradley N Collins, and Danielle E McCarthy for serving on the independent monitoring committee for this study.

\section{Conflicts of Interest}

LCA has stock in Welltok Inc and receives royalties from the licensing of Text2Quit to Welltok, Inc. MPE receives research funding support from Pfizer, Inc ("Diffusion of Tobacco Control Fundamentals to Other Large Chinese Cities," MPE, Principal Investigator). The other authors have no conflicts of interest to declare.

\section{Multimedia Appendix 1}

CONSORT - EHEALTH checklist (V 1.6.1).

[PDF File (Adobe PDF File), 2MB-Multimedia Appendix 1]

\section{References}

1. The Health Consequences of Smoking-50 Years of Progress: A Report of the Surgeon General. Washington, DC: US Department of Health and Human Services; 2014.

2. Babb S, Malarcher A, Schauer G, Asman K, Jamal A. Quitting smoking among adults - United States, 2000-2015. MMWR Morb Mortal Wkly Rep 2017 Jan 6;65(52):1457-1464 [FREE Full text] [doi: 10.15585/mmwr.mm6552a1] [Medline: 28056007]

3. US National Cancer Institute. Division of Cancer Control and Population Sciences. 2017. Monograph 22. A sociological approach to addressing tobacco-related health disparities URL: https://cancercontrol.cancer.gov/brp/tcrb/monographs/22/

4. Drope J, Liber AC, Cahn Z, Stoklosa M, Kennedy R, Douglas CE, et al. Who's still smoking? Disparities in adult cigarette smoking prevalence in the United States. CA Cancer J Clin 2018;68(2):106-115 [FREE Full text] [doi: 10.3322/caac.21444] [Medline: 29384589]

5. Jamal A, Phillips E, Gentzke AS, Homa DM, Babb SD, King BA, et al. Current cigarette smoking among adults - United States, 2016. MMWR Morb Mortal Wkly Rep 2018 Jan 19;67(2):53-59 [FREE Full text] [doi: 10.15585/mmwr.mm6702a1] [Medline: 29346338]

6. Hiscock R, Bauld L, Amos A, Fidler JA, Munafò M. Socioeconomic status and smoking: a review. Ann N Y Acad Sci 2012;1248:107-123. [doi: 10.1111/j.1749-6632.2011.06202.x] [Medline: 22092035]

7. Centers for Disease Control and Prevention. 2013. CDC Health Disparities and Inequalities Report - United States, 2013 URL: https://www.cdc.gov/mmwr/pdf/other/su6203.pdf 
8. Businelle MS, Kendzor DE, Reitzel LR, Costello TJ, Cofta-Woerpel L, Li Y, et al. Mechanisms linking socioeconomic status to smoking cessation: a structural equation modeling approach. Health Psychol 2010;29(3):262-273 [FREE Full text] [doi: 10.1037/a0019285] [Medline: 20496980]

9. Baer RA, Smith GT, Hopkins J, Krietemeyer J, Toney L. Using self-report assessment methods to explore facets of mindfulness. Assessment 2006;13(1):27-45. [doi: 10.1177/1073191105283504] [Medline: 16443717]

10. Kabat-Zinn J. Full Catastrophe Living: Using the Wisdom of Your Body and Mind to Face Stress, Pain, and Illness. New York: Delacorte Press; 1990.

11. Brewer JA, Mallik S, Babuscio TA, Nich C, Johnson HE, Deleone CM, et al. Mindfulness training for smoking cessation: results from a randomized controlled trial. Drug Alcohol Depend 2011;119(1-2):72-80 [FREE Full text] [doi: 10.1016/j.drugalcdep.2011.05.027] [Medline: 21723049]

12. Vidrine JI, Spears CA, Heppner WL, Reitzel LR, Marcus MT, Cinciripini PM, et al. Efficacy of mindfulness-based addiction treatment (MBAT) for smoking cessation and lapse recovery: a randomized clinical trial. J Consult Clin Psychol 2016;84(9):824-838 [FREE Full text] [doi: 10.1037/ccp0000117] [Medline: 27213492]

13. Oikonomou MT, Arvanitis M, Sokolove RL. Mindfulness training for smoking cessation: a meta-analysis of randomized-controlled trials. J Health Psychol 2017;22(14):1841-1850. [doi: 10.1177/1359105316637667] [Medline: 27044630]

14. Davis JM, Goldberg SB, Anderson MC, Manley AR, Smith SS, Baker TB. Randomized trial on mindfulness training for smokers targeted to a disadvantaged population. Subst Use Misuse 2014 Apr;49(5):571-585 [FREE Full text] [doi: 10.3109/10826084.2013.770025] [Medline: 24611852]

15. Davis JM, Manley AR, Goldberg SB, Smith SS, Jorenby DE. Randomized trial comparing mindfulness training for smokers to a matched control. J Subst Abuse Treat 2014;47(3):213-221 [FREE Full text] [doi: 10.1016/j.jsat.2014.04.005] [Medline: 24957302]

16. Witkiewitz K, Greenfield BL, Bowen S. Mindfulness-based relapse prevention with racial and ethnic minority women. Addict Behav 2013 Dec;38(12):2821-2824 [FREE Full text] [doi: 10.1016/j.addbeh.2013.08.018] [Medline: 24018224]

17. Spears CA, Houchins SC, Bamatter WP, Barrueco S, Hoover DS, Perskaudas R. Perceptions of mindfulness in a low-income, primarily African American treatment-seeking sample. Mindfulness (N Y) 2017 Dec;8(6):1532-1543 [FREE Full text] [Medline: 29333200]

18. Heron KE, Smyth JM. Ecological momentary interventions: incorporating mobile technology into psychosocial and health behaviour treatments. Br J Health Psychol 2010 Feb;15(Pt 1):1-39 [FREE Full text] [doi: 10.1348/135910709X466063] [Medline: 19646331]

19. Sliwinski J, Katsikitis M, Jones CM. A review of interactive technologies as support tools for the cultivation of mindfulness. Mindfulness 2017;8(5):1150-1159. [doi: 10.1007/s12671-017-0698-x]

20. Fish J, Brimson J, Lynch S. Mindfulness interventions delivered by technology without facilitator involvement: what research exists and what are the clinical outcomes? Mindfulness (N Y) 2016;7(5):1011-1023 [FREE Full text] [doi: 10.1007/s12671-016-0548-2] [Medline: 27642370]

21. Davis JM, Manley AR, Goldberg SB, Stankevitz KA, Smith SS. Mindfulness training for smokers via web-based video instruction with phone support: a prospective observational study. BMC Complement Altern Med 2015 Mar 29;15:95 [FREE Full text] [doi: 10.1186/s12906-015-0618-3] [Medline: 25886752]

22. Bricker JB, Mull KE, Kientz JA, Vilardaga R, Mercer LD, Akioka KJ, et al. Randomized, controlled pilot trial of a smartphone app for smoking cessation using acceptance and commitment therapy. Drug Alcohol Depend 2014 Oct 01;143:87-94 [FREE Full text] [doi: 10.1016/j.drugalcdep.2014.07.006] [Medline: 25085225]

23. Garrison KA, Pal P, O'Malley SS, Pittman BP, Gueorguieva R, Rojiani R, et al. Craving to quit: a randomized controlled trial of smartphone app-based mindfulness training for smoking cessation. Nicotine Tob Res 2018 Jun 18 (forthcoming). [doi: 10.1093/ntr/nty126] [Medline: 29917096]

24. Mani M, Kavanagh DJ, Hides L, Stoyanov SR. Review and evaluation of mindfulness-based iPhone apps. JMIR Mhealth Uhealth 2015 Aug 19;3(3):e82 [FREE Full text] [doi: 10.2196/mhealth.4328] [Medline: 26290327]

25. Free C, Knight R, Robertson S, Whittaker R, Edwards P, Zhou W, et al. Smoking cessation support delivered via mobile phone text messaging (txt2stop): a single-blind, randomised trial. Lancet $2011 \mathrm{Jul}$ 2;378(9785):49-55 [FREE Full text] [doi: 10.1016/S0140-6736(11)60701-0] [Medline: 21722952]

26. Whittaker R, McRobbie H, Bullen C, Rodgers A, Gu Y. Mobile phone-based interventions for smoking cessation. Cochrane Database Syst Rev 2016 Apr 10;4:CD006611 [FREE Full text] [doi: 10.1002/14651858.CD006611.pub4] [Medline: 27060875]

27. Armanasco AA, Miller YD, Fjeldsoe BS, Marshall AL. Preventive health behavior change text message interventions: a meta-analysis. Am J Prev Med 2017 Mar;52(3):391-402. [doi: 10.1016/j.amepre.2016.10.042] [Medline: 28073656]

28. Abroms LC, Boal AL, Simmens SJ, Mendel JA, Windsor RA. A randomized trial of Text2Quit: a text messaging program for smoking cessation. Am J Prev Med 2014 Sep;47(3):242-250 [FREE Full text] [doi: 10.1016/j.amepre.2014.04.010] [Medline: 24913220] 
29. Scott-Sheldon LA, Lantini R, Jennings EG, Thind H, Rosen RK, Salmoirago-Blotcher E, et al. Text messaging-based interventions for smoking cessation: a systematic review and meta-analysis. JMIR Mhealth Uhealth 2016 May 20;4(2):e49. [doi: 10.2196/mhealth.5436] [Medline: 27207211]

30. Spohr SA, Nandy R, Gandhiraj D, Vemulapalli A, Anne S, Walters ST. Efficacy of SMS text message interventions for smoking cessation: a meta-analysis. J Subst Abuse Treat 2015 Sep;56:1-10. [doi: 10.1016/j.jsat.2015.01.011] [Medline: 25720333]

31. Pew Research Center. 2018. Mobile Fact Sheet URL: http://www.pewinternet.org/fact-sheet/mobile/[WebCite Cache ID 6zycrGIuw]

32. Smith A. Pew Research Center. 2011. Americans and Text Messaging URL: http://pewinternet.org/Reports/2011/ Cell-Phone-Texting-2011.aspx[WebCite Cache ID 6zycTUE04]

33. McCurdie T, Taneva S, Casselman M, Yeung M, McDaniel C, Ho W, et al. mHealth consumer apps: the case for user-centered design. Biomed Instrum Technol 2012;Suppl:49-56. [doi: 10.2345/0899-8205-46.s2.49] [Medline: 23039777]

34. Abroms LC, Whittaker R, Free C, Mendel van Alstyne J, Schindler-Ruwisch JM. Developing and pretesting a text messaging program for health behavior change: recommended steps. JMIR Mhealth Uhealth 2015 Dec 21;3(4):e107 [FREE Full text] [doi: 10.2196/mhealth.4917] [Medline: 26690917]

35. Bock BC, Rosen RK, Barnett NP, Thind H, Walaska K, Foster R, et al. Translating behavioral interventions onto mHealth platforms: developing text message interventions for smoking and alcohol. JMIR Mhealth Uhealth 2015 Feb 24;3(1):e22 [FREE Full text] [doi: 10.2196/mhealth.3779] [Medline: 25714907]

36. Spears CA, Bell SA, Scarlett CA, Anderson NK, Cottrell-Daniels C, Lotfalian S, et al. Text messaging to enhance mindfulness-based smoking cessation treatment: program development through qualitative research. JMIR Mhealth Uhealth 2019 Jan 7;7(1):e11246 [FREE Full text] [doi: 10.2196/11246] [Medline: 30617043]

37. Davis TC, Crouch MA, Long SW, Jackson RH, Bates P, George RB, et al. Rapid assessment of literacy levels of adult primary care patients. Fam Med 1991 Aug;23(6):433-435. [Medline: 1936717]

38. Spitzer RL, Kroenke K, Williams JB. Validation and utility of a self-report version of PRIME-MD: the PHQ primary care study. Primary care evaluation of mental disorders. Patient Health Questionnaire. J Am Med Assoc 1999 Nov 10;282(18):1737-1744. [Medline: $\underline{10568646]}$

39. Kroenke K, Spitzer RL, Williams JB. The Patient Health Questionnaire-2: validity of a two-item depression screener. Med Care 2003 Nov;41(11):1284-1292. [doi: 10.1097/01.MLR.0000093487.78664.3C] [Medline: 14583691]

40. Clinical Practice Guideline Treating Tobacco Use and Dependence 2008 Update Panel, Liaisons, and Staff. A clinical practice guideline for treating tobacco use and dependence: 2008 update. A US public health service report. Am J Prev Med 2008 Aug;35(2):158-176 [FREE Full text] [doi: 10.1016/j.amepre.2008.04.009] [Medline: 18617085]

41. Segal ZV, Williams JM, Teasdale JD. Mindfulness-Based Cognitive Therapy for Depression: A New Approach to Preventing Relapse. New York: The Guilford Press; 2001.

42. United States Census Bureau. 2018. Poverty Thresholds URL: https://www.census.gov/data/tables/time-series/demo/ income-poverty/historical-poverty-thresholds.html

43. Kozlowski LT, Porter CQ, Orleans CT, Pope MA, Heatherton T. Predicting smoking cessation with self-reported measures of nicotine dependence: FTQ, FTND, and HSI. Drug Alcohol Depend 1994 Feb;34(3):211-216. [Medline: $\underline{8033758]}$

44. Hedeker D, Mermelstein RJ, Demirtas H. Analysis of binary outcomes with missing data: missing = smoking, last observation carried forward, and a little multiple imputation. Addiction 2007 Oct;102(10):1564-1573. [doi:

10.1111/j.1360-0443.2007.01946.x] [Medline: 17854333]

45. Blankers M, Smit ES, van der Pol P, de Vries H, Hoving C, van Laar M. The missing=smoking assumption: a fallacy in internet-based smoking cessation trials? Nicotine Tob Res 2016 Jan;18(1):25-33. [doi: 10.1093/ntr/ntv055] [Medline: 25744969]

46. Senn S. Testing for baseline balance in clinical trials. Stat Med 1994 Sep 15;13(17):1715-1726. [Medline: 7997705]

47. Pocock SJ, Assmann SE, Enos LE, Kasten LE. Subgroup analysis, covariate adjustment and baseline comparisons in clinical trial reporting: current practice and problems. Stat Med 2002 Oct 15;21(19):2917-2930. [doi: 10.1002/sim.1296] [Medline: $\underline{12325108]}$

48. Abroms LC, Ahuja M, Kodl Y, Thaweethai L, Sims J, Winickoff JP, et al. Text2Quit: results from a pilot test of a personalized, interactive mobile health smoking cessation program. J Health Commun 2012;17(Suppl 1):44-53 [FREE Full text] [doi: 10.1080/10810730.2011.649159] [Medline: 22548598]

49. Heminger CL, Schindler-Ruwisch JM, Abroms LC. Smoking cessation support for pregnant women: role of mobile technology. Subst Abuse Rehabil 2016;7:15-26 [FREE Full text] [doi: 10.2147/SAR.S84239] [Medline: 27110146]

50. Daly AT, Deshmukh AA, Vidrine DJ, Prokhorov AV, Frank SG, Tahay PD, et al. Cost-effectiveness analysis of smoking cessation interventions using cell phones in a low-income population. Tob Control 2019;28(1):88-94. [doi: 10.1136/tobaccocontrol-2017-054229] [Medline: 29886411]

51. Heminger CL, Boal AL, Zumer M, Abroms LC. Text2Quit: an analysis of participant engagement in the mobile smoking cessation program. Am J Drug Alcohol Abuse 2016;42(4):450-458. [doi: 10.3109/00952990.2016.1149591] [Medline: 27120396] 
52. Zeng EY, Heffner JL, Copeland WK, Mull KE, Bricker JB. Get with the program: adherence to a smartphone app for smoking cessation. Addict Behav 2016 Dec;63:120-124 [FREE Full text] [doi: 10.1016/j.addbeh.2016.07.007] [Medline: 27454354]

53. Bricker JB, Copeland W, Mull KE, Zeng EY, Watson NL, Akioka KJ, et al. Single-arm trial of the second version of an acceptance \& commitment therapy smartphone application for smoking cessation. Drug Alcohol Depend 2017 Jan 1;170:37-42 [FREE Full text] [doi: 10.1016/j.drugalcdep.2016.10.029] [Medline: 27870987]

54. Krebs P, Duncan DT. Health app use among US mobile phone owners: a national survey. JMIR Mhealth Uhealth 2015 Nov 4;3(4):e101 [FREE Full text] [doi: 10.2196/mhealth.4924] [Medline: 26537656]

55. Thrul J, Klein AB, Ramo DE. Smoking cessation intervention on Facebook: which content generates the best engagement? J Med Internet Res 2015 Nov 11;17(11):e244 [FREE Full text] [doi: 10.2196/jmir.4575] [Medline: 26561529]

56. Strecher VJ, McClure J, Alexander G, Chakraborty B, Nair V, Konkel J, et al. The role of engagement in a tailored web-based smoking cessation program: randomized controlled trial. J Med Internet Res 2008 Nov 4;10(5):e36 [FREE Full text] [doi: 10.2196/jmir.1002] [Medline: 18984557]

57. Krebs P, Prochaska JO, Rossi JS. A meta-analysis of computer-tailored interventions for health behavior change. Prev Med 2010;51(3-4):214-221 [FREE Full text] [doi: 10.1016/j.ypmed.2010.06.004] [Medline: 20558196]

58. Lloyd A, White R, Eames C, Crane R. The utility of home-practice in mindfulness-based group interventions: a systematic review. Mindfulness (N Y) 2018;9(3):673-692 [FREE Full text] [doi: 10.1007/s12671-017-0813-z] [Medline: 29875880]

59. Vettese LC, Toneatto T, Stea JN, Nguyen L, Wang JJ. Do mindfulness meditation participants do their homework? And does it make a difference? A review of the empirical evidence. J Cogn Psychother 2009;23(3):198-225 [FREE Full text] [doi: 10.1891/0889-8391.23.3.198]

60. Parsons CE, Crane C, Parsons LJ, Fjorback LO, Kuyken W. Home practice in mindfulness-based cognitive therapy and mindfulness-based stress reduction: a systematic review and meta-analysis of participants' mindfulness practice and its association with outcomes. Behav Res Ther 2017 Aug;95:29-41 [FREE Full text] [doi: 10.1016/j.brat.2017.05.004] [Medline: 28527330]

61. Grau LE, Pham T, O'Leary T, Weiss J, Toll B, Bernstein SL. Smokers' perspectives on texting for tobacco dependence treatment: a qualitative analysis. Nicotine Tob Res 2017 Mar 1;19(3):307-313. [doi: 10.1093/ntr/ntw184] [Medline: 27613935]

62. Douglas N, Free C. 'Someone batting in my corner': experiences of smoking-cessation support via text message. Br J Gen Pract 2013 Nov;63(616):e768-e776 [FREE Full text] [doi: 10.3399/bjgp13X674459] [Medline: 24267860]

63. Smith A. Pew Research Center. 2017. Record Shares of Americans Now Own Smartphones, Have Home Broadband URL: http://www.pewresearch.org/fact-tank/2017/01/12/evolution-of-technology/[WebCite Cache ID 731XLweZn]

64. Businelle MS, Ma P, Kendzor DE, Frank SG, Vidrine DJ, Wetter DW. An ecological momentary intervention for smoking cessation: evaluation of feasibility and effectiveness. J Med Internet Res 2016 Dec 12;18(12):e321 [FREE Full text] [doi: 10.2196/jmir.6058] [Medline: 27956375]

65. Little RJ, Yau LH. Statistical techniques for analyzing data from prevention trials: treatment of no-shows using Rubin's causal model. Psychol Methods 1998;3(2):147-159 [FREE Full text]

\author{
Abbreviations \\ CO: carbon monoxide \\ MBAT: Mindfulness-Based Addiction Treatment \\ mHealth: mobile health \\ PHQ: Patient Health Questionnaire \\ RCT: randomized controlled trial \\ RR: risk ratio \\ SES: socioeconomic status
}

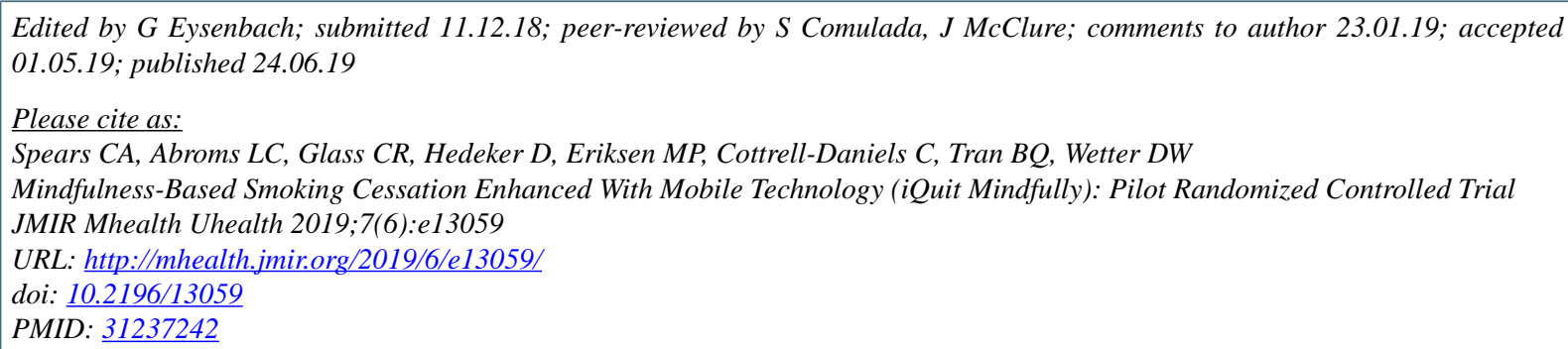


CClaire Adams Spears, Lorien C Abroms, Carol R Glass, Donald Hedeker, Michael P Eriksen, Cherell Cottrell-Daniels, Binh Q Tran, David W Wetter. Originally published in JMIR Mhealth and Uhealth (http://mhealth.jmir.org), 24.06.2019. This is an open-access article distributed under the terms of the Creative Commons Attribution License (https://creativecommons.org/licenses/by/4.0/), which permits unrestricted use, distribution, and reproduction in any medium, provided the original work, first published in JMIR mhealth and uhealth, is properly cited. The complete bibliographic information, a link to the original publication on http://mhealth.jmir.org/, as well as this copyright and license information must be included. 